\title{
IN VITRO EQUIVALENCE STUDY OF DIFFERENT DOSES OF CARBAMAZEPINE REFERENCE TABLETS USING USP APPARATUSES 2 AND 4
}

\author{
JOSE RAUL MEDINA-LOPEZ, LUIS ANTONIO CEDILLO-DÍAZ, MARCELA HURTADO \\ Departamento Sistemas Biológicos, Universidad Autónoma Metropolitana-Xochimilco, Mexico City, Mexico \\ Email: rmlopez@correo.xoc.uam.mx
}

Received: 21 Mar 2019, Revised and Accepted: 24 May 2019

\section{ABSTRACT}

Objective: To perform an in vitro equivalence study of two doses of carbamazepine reference tablets sold in the local market under hydrodynamic conditions of USP Apparatus 4, a dissolution apparatus that better simulates the human gastrointestinal tract. Results were compared with dissolution official conditions using USP Apparatus 2.

Methods: Dissolution profiles of both formulations were carried out with an automated USP Apparatus 2 at 75 rpm and 900 ml of dissolution medium. USP Apparatus 4 with laminar flow at $16 \mathrm{ml} / \mathrm{min}$ and $22.6 \mathrm{~mm}$ cells were used. $1 \%$ lauryl sulfate aqueous solution at $37.0 \pm 0.5{ }^{\circ} \mathrm{C}$ was used as dissolution medium. Spectrophotometric determination of drug at $285 \mathrm{~nm}$ was carried out during 60 min. Dissolution profiles were compared with model-independent and-dependent approaches.

Results: When comparing dissolution profiles of low $v s$. high dose similar profiles were found $\left(f_{2}>50\right)$ in each dissolution apparatus, however, when the same dose was compared, USP 2 vs. USP 4, opposite results were obtained. Comparison of mean dissolution time and dissolution efficiency data corroborates these results. Weibull function was the best mathematical model that described the in vitro dissolution performance of carbamazepine. No significant differences were found in Td values (low vs. high dose) but opposite results were also found with USP 2 vs. USP 4.

Conclusion: Equivalent dissolution performance of two doses of carbamazepine reference tablets were found in each USP dissolution apparatus. The main problem identified in this comparative study is the low dissolution rate and extent found with USP Apparatus 4. More research on this field is necessary for all available doses of reference drug products since the quality of generic formulations depends on the quality of references.

Keywords: Carbamazepine, Flow-through cell method, Reference drug products, USP Apparatus 4

(C) 2019 The Authors. Published by Innovare Academic Sciences Pvt Ltd. This is an open access article under the CC BY license (http://creativecommons.org/licenses/by/4.0/] DOI: http://dx.doi.org/10.22159/ijap.2019v11i4.33174

\section{INTRODUCTION}

Dissolution test is an important tool to ensure lot-to-lot good quality and after some manufacture, changes as well as for determination of interchangeability among generic formulations. These formulations have the same pharmacological effect with the benefit of lower costs for patients and hospitals. Generic drug products should demonstrate the same in vitro dissolution performance of reference drug products so, quality of generic drug products depends of the quality of references. Due to the high cost of bioequivalence studies and information of Biopharmaceutics Classification System (BCS) about solubility and permeability of some drugs, Guidelines for Industry-based on BCS have established criteria by which bioequivalence studies can be replaced by in vitro dissolution studies [1]. This waiver is based mainly on the fulfillment of $f_{2}$ similarity factor between dissolution profiles of test and reference $\left(f_{2}>50\right)$ using dissolution media with $\mathrm{pH}$ of physiological relevance as well as compliance with related criteria to the excipients used in the formulation manufacture [2]. Some biowaiver monographs have been published for class I and III drugs (high solubility drugs) [3] but for its physicochemical and clinical characteristics, no biowaiver monograph has been published for carbamazepine.

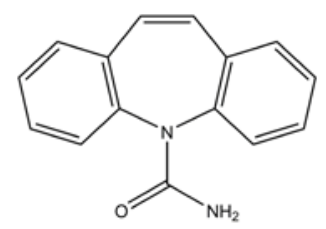

Fig. 1: Molecular structure of carbamazepine

Carbamazepine is a poorly soluble drug with a narrow therapeutic window used to treat epilepsy and other neurological disorders as trigeminal neuralgia [4]. Molecular structure of carbamazepine is shown in fig. 1 . The drug is available as generic drug products and Mexican health authorities request bioequivalence studies to approve the marketing of these formulations. Considering BCS criteria carbamazepine has been classified as a class II drug (low solubility/high permeability) and for its low solubility, dissolution problems of two different doses in the same volume of dissolution medium could be observed. Class II drugs are expected to have a dissolution-limited absorption and a significant in vitro/in vivo correlation (IVIVC) should be expected using a well-designed in vitro dissolution test.

For multiple strengths of immediate-release products with linear kinetics, the bioequivalence study may be performed at the highest strength and waivers of in vivo studies may be granted on lower strengths, based on an adequate dissolution test, provided the lower strengths are proportionately similar in composition [5]. It is possible that this assertion does not apply to carbamazepine however, it is important to investigate the in vitro dissolution performance of two doses of carbamazepine reference tablets under hydrodynamic environments generated by commonly used dissolution apparatuses with the aim of gather information to suggest a biowaiver mechanism for carbamazepine drug products, starting at least, with the available doses of reference and pharmacopeial conditions.

Official dissolution test for carbamazepine tablets is described in United States Pharmacopoeia (USP) [6]. The method indicates the use of USP Apparatus 2 (paddle) at $75 \mathrm{rpm}$ and $900 \mathrm{ml}$ of $1 \%$ sodium lauryl sulfate aqueous solution at $37.0 \pm 0.5^{\circ} \mathrm{C}$ as dissolution medium. Under these conditions and for carbamazepine immediate-release tablets labeled as 200-mg there are two tests with the following times and tolerances: TEST 2 between 45 and 75\% of the labeled amount of carbamazepine is dissolved in $15 \mathrm{~min}$; not less than $75 \%$ $(Q)$ of the labeled amount of carbamazepine is dissolved in $60 \mathrm{~min}$ and TEST 3 between 60 and $85 \%$ of the labeled amount of carbamazepine is dissolved in $15 \mathrm{~min}$; not less than $75 \%(Q)$ of the 
labeled amount of carbamazepine is dissolved in 60 min. However, some authors reported lack of correlation between in vitro data using these conditions and in vivo results $[7,8]$.

A dissolution equipment different to USP Apparatus 1 (basket) and 2 (paddle) is USP Apparatus 4 (flow-through cell method) [9, 10]. Its advantages, over USP basket and paddle apparatuses, have been widely demonstrated especially in the study of dissolution performance of poorly soluble drugs $[11,12]$. The flow-through cell method has a continuous extraction of the drug, simulating the absorption into the systemic circulation, generating an intermittent flow of dissolution medium into the cells where the tablets are placed [13]. USP Apparatus 4 can be used as an open system that operates under sink conditions which facilitates the dissolution of poorly soluble drugs as well as changing the dissolution medium throughout the test [14]. Flow-through cell method better simulates the hydrodynamic environment found in the gastrointestinal tract and some authors have demonstrated that in vitro data obtained with flow-through cell method better reflect in vivo performance of drugs with solubility problems $[15,16]$. Despite the advantages of USP Apparatus 4, information about dissolution performance of commercially available doses of carbamazepine reference tablets under hydrodynamic environment generated by the flow-through cell method is scarce.

The main objective of this in vitro equivalence study was to evaluate the release performance of two doses of carbamazepine reference tablets under the hydrodynamic environment generated by USP Apparatus 4. Data obtained were compared with the pharmacopeial test that uses USP Apparatus 2. The results could be of interest for pharmaceutical laboratories or health authorities that classify some drug products as a reference to be used in dissolution and bioequivalence studies.

\section{MATERIALS AND METHODS}

\section{Materials}

In this pharmaceutical equivalence study carbamazepine tablets (Tegretol $® 200-\mathrm{mg}$, lot TL005, round tablets of $9 \times 3.7 \mathrm{~mm}$ and Tegretol ${ }^{\circledR}$ 400-mg, lot TL534, cuboid tablets of $17 \times 5.5 \times 5.1 \mathrm{~mm}$; Novartis Farmacéutica SA de CV) from the Mexican market were used. National health authorities (COFEPRIS) has established this brand as a reference for bioequivalence studies [17]. Sodium lauryl sulfate was purchased from Distribuidora Química Lufra-México. Carbamazepine standard was purchased from Sigma-Aldrich Co. (St. Louis MO, USA).

\section{Content uniformity and assay}

Content uniformity and assay tests were performed on both drug products, according to the procedures described in USP [6].

\section{Dissolution profiles \\ USP Apparatus 2}

Dissolution profiles of carbamazepine were determined according to USP test [6] in an automated USP paddle apparatus (Sotax AT-7 Smart, Switzerland) with a piston pump (Sotax CY7-50, Switzerland). An UV/Vis spectrophotometer with $1 \mathrm{~mm}$ flow cells (Perkin Elmer Lambda 35, USA) was used. All equipment and data generated were controlled by specific software designed by Sotax. Both doses of carbamazepine reference tablets were sprinkled on $900 \mathrm{ml}$ of $1 \%$ sodium lauryl sulfate aqueous solution at $37.0 \pm 0.5^{\circ} \mathrm{C}$ as dissolution medium. The rotational speed of $75 \mathrm{rpm}$ was tested. Sequential sampling using $0.45 \mu \mathrm{m}$ nitrocellulose filters (Millipore ${ }^{\circledR}$ ) occurred over $60 \mathrm{~min}$ at regular $5 \mathrm{~min}$ intervals with 12 replicates. The amount of carbamazepine dissolved was determined with a standard calibration curve at $285 \mathrm{~nm}$.

\section{USP Apparatus 4}

Dissolution profiles of both doses of carbamazepine tablets were obtained in an automated flow-through cell apparatus 4 (Sotax CE6, Sotax AG, Switzerland) with $22.6 \mathrm{~mm}$ cells (i.d.) and a piston pump (Sotax CY7-50, Sotax AG, Switzerland). Laminar flow (with a bed of 6 $\mathrm{g}$ of glass beads) was used. The degassed dissolution medium, 1\% sodium lauryl sulfate aqueous solution at $37.0 \pm 0.5^{\circ} \mathrm{C}$ was pumped at a flow rate of $16 \mathrm{ml} / \mathrm{min}$. An open system was used, without recycling the dissolution medium. Sequential sampling using nitrocellulose filters was set at regular 5 min intervals over $60 \mathrm{~min}$, with 12 replicates. The amount of carbamazepine dissolved was determined in an UV/Vis spectrophotometer with $1 \mathrm{~mm}$ cells (Perkin Elmer Lambda 10, USA) at $285 \mathrm{~nm}$. For every trial, a standard calibration curve was prepared.

\section{Data analysis}

Dissolution profiles of carbamazepine (low vs. high dose) were compared using model-independent and-dependent methods. For model-independent methods $f_{2}$ similarity factor, mean dissolution time (MDT) and dissolution efficiency (DE) were calculated. Mean values were compared by a Student's t-test and significant differences were considered if $* \mathrm{P}<0.05$. For model-dependent comparisons, dissolution data were adjusted to First-order, Higuchi, Korsmeyer-Peppas, Hixson-Crowell, Makoid-Banakar, Weibull and Logistic model. The model with the highest determination coefficient $\left(\mathrm{R}^{2}\right.$ adjusted) and lowest Akaike information criterion (AIC) was chosen as the best-fit model [18]. Data analysis was carried out using the Excel add-in DDSolver program [19]. Mathematical equations used to fit carbamazepine dissolution data are shown in table 1 .

Table 1: Mathematical equations used to fit dissolution data

\begin{tabular}{lc}
\hline Model & Equation \\
\hline First-order & $F=100 \cdot\left(1-e^{-k_{1} \cdot t}\right)$ \\
Higuchi & $F=k_{H} \cdot t^{0.5}$ \\
Korsmeyer-Peppas & $F=k_{K P} \cdot t^{n}$ \\
Hixson-Crowell & $F=100\left[1-\left(1-k_{H C} \cdot t\right)^{3}\right]$ \\
Makoid-Banakar & $F=k_{M B} \cdot t^{n} \cdot e^{-k \cdot t}$ \\
Weibull & $F=F_{\max } \cdot\left(1-e^{-\frac{t^{\beta}}{\alpha}}\right)$ \\
Logistic & $F=100 \cdot \frac{e^{\alpha+\beta \cdot \log (t)}}{1+e^{\alpha+\beta \cdot \log (t)}}$ \\
\hline
\end{tabular}

\section{RESULTS AND DISCUSSION}

\section{Content uniformity and assay}

All carbamazepine drug products were within USP limits. The percentages of carbamazepine on content uniformity test ranged from $85-115 \%$ and assay test between $90-110 \%$. Results are shown in table 2 .

\section{In vitro dissolution performance}

Dissolution profiles of two doses of carbamazepine reference tablets, in both USP Apparatuses, are shown in fig. 2. To compare the dissolution process between doses, $Y$-axis is expressed as the percentage of drug dissolved. 
Table 2: Content uniformity and assay results, mean, $n=10^{*}, n=3 \dagger$

\begin{tabular}{lll}
\hline Dose & Content uniformity (min-max)* & Assay (\%)† \\
Low & $95.26-96.49$ & 96.10 \\
High & $91.96-94.83$ & 93.85 \\
\hline
\end{tabular}

USP paddle apparatus

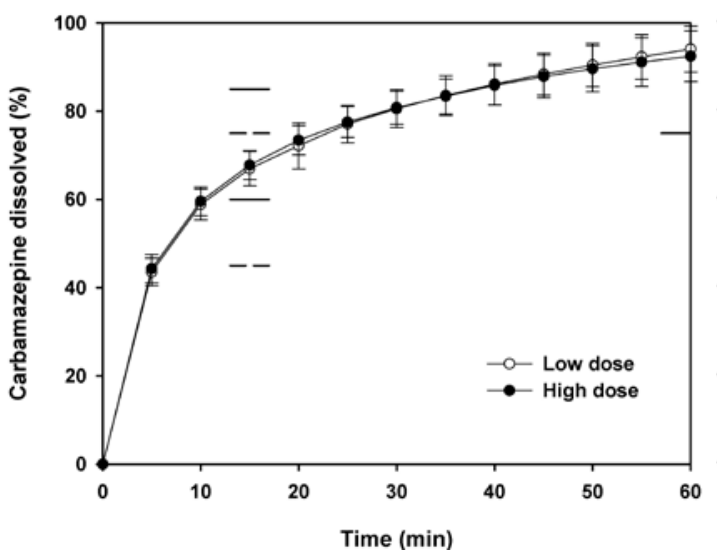

Flow-through cell method

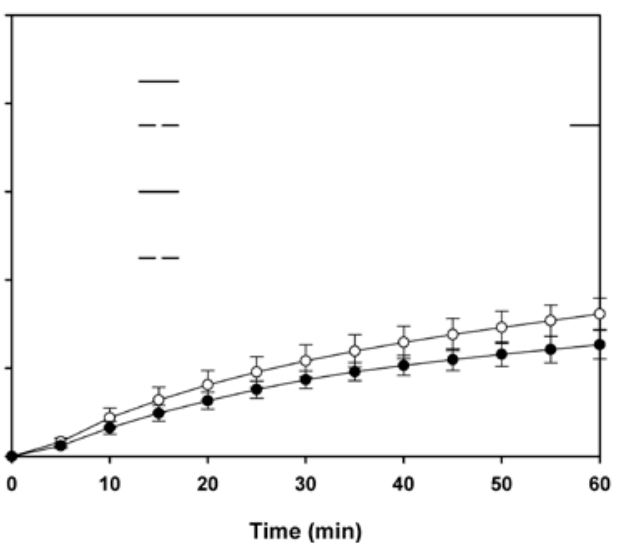

Fig. 2: Dissolution profiles of carbamazepine from two doses of reference tablets. Slashed line shows tolerances of TEST 2 and continuous line shows tolerances of TEST 3. mean $\pm \mathrm{SD}, n=12$

Carbamazepine 200-mg reference tablets et al. l dissolution tolerances only when tests were carried out with USP Apparatus 2. Tolerance of USP TEST 2 at $15 \mathrm{~min}$ is $45-75 \%$ of drug dissolved and at 60 min not less than $75 \%$ of drug dissolved should be found while tolerance of TEST 3 at $15 \mathrm{~min}$ is $60-85 \%$ of drug dissolved and at 60 min not less than $75 \%$ of drug dissolved should be found. These criteria were also fulfilled by carbamazepine 400-mg tablets. With flow-through cell method, any dissolution criteria were fulfilled.

In each USP dissolution apparatus, similar dissolution profiles of low $v s$. high dose were found, $f_{2}=94.46$ when USP Apparatus 2 was used and $f_{2}=66.51$ when USP Apparatus 4 was used. On the other hand, and despite the obvious differences in dissolution profiles of both carbamazepine doses, between USP Apparatuses 2 and $4, f_{2}$ similarity factors were also calculated and results were 12.99 when the dose of 200-mg was compared and 11.36 when dose of 400-mg was compared. A limited dissolution of 200-mg reference tablets was also reported by Medina et al., [20] when simulated gastric fluid without pepsin and flow-through cell method were used. Values of $17.99 \%$ as drug dissolved at $60 \mathrm{~min}$ and $9.81 \%$ as DE were found.

With USP Apparatus 4 both formulations showed a slower dissolution rate than that found with USP paddle apparatus. Some authors have published that this performance can be explained by the hydrodynamic conditions found in USP Apparatus 4, where there are no agitation mechanisms and the dosage form and drug particles are continuously exposed to a uniform laminar flow, similar to the natural environment of the gastrointestinal tract, causing a different dissolution pattern [21]. In the flow-through cell method, cell size, glass beads and flow rate are critical factors to form this dissolution pattern. Considering USP Apparatus 4 as a dissolution apparatus that better simulates in vivo conditions and for the low dissolution rate and extent observed with this apparatus clinical problems of carbamazepine could be explained. $30 \%$ of patients with focal epilepsy do not respond to maximum dosages of carbamazepine resulting in the need to administer polytherapy with additional antiepileptic drugs to control seizures [22].

\section{Model-independent comparisons}

Percentage of carbamazepine dissolved at 15 and $60 \mathrm{~min}$ and model-independent parameters MDT and DE mean values standard error medium (SEM) are shown in table 3. Data of low vs. high dose were compared and significant differences were found only in the percentage of drug dissolved at 15 and $60 \mathrm{~min}$ with USP Apparatus $4\left({ }^{*} \mathrm{P}<0.05\right)$.

Table 3: Model-independent parameters of carbamazepine, mean \pm SEM, $n=12$

\begin{tabular}{llllll}
\hline USP Apparatus & Dose & Diss. at 15 min (\%) & Diss. at 60 min (\%) & MDT (min) & DE (\%) \\
\hline 2 & Low & $66.97 \pm 1.13$ & $94.05 \pm 1.50$ & $73.90 \pm 1.18$ & $12.85 \pm 0.16$ \\
& High & $67.75 \pm 0.95$ & $92.77 \pm 1.66$ & $11.95 \pm 0.43$ \\
4 & Low & $12.77 \pm 0.83$ & $32.26 \pm 1.03$ & $23.68 \pm 0.67$ \\
& High & $9.76 \pm 0.51^{*}$ & $25.30 \pm 0.95^{*}$ & $19.58 \pm 0.85$ & $23.31 \pm 0.44$ \\
\hline
\end{tabular}

$* \mathrm{P}<0.05$, Low vs. High dose.

Dissolution performance of carbamazepine from reference tablets shows a dependence on the hydrodynamic conditions to which tablets were subjected. Statistical comparison of model-independent parameters MDT and DE confirm this result. No significant differences were found between doses in each USP apparatus $\left({ }^{*} \mathrm{P}>0.05\right)$ but between USP apparatuses each dose was totally different.

Dissolution profiles comparison were carried out with modelindependent parameters MDT and DE. MDT is the time interval necessary to dissolve $63.2 \%$ of the drug contained in the pharmaceutical dosage form and it was calculated according to statistical moment's theory [23]. On the other hand, DE is the area under the dissolution curve up to a certain time $t$, expressed as a percentage of the area of the rectangle described by $100 \%$ dissolution in the same time [24]; so, while MDT is related to dissolution rate, DE is related to drug dissolution extent. Cardot et al., [25] remark that these model-independent parameters have been proposed as adequate parameters for some IVIVC levels. IVIVC Level $B$ is based on the comparison of parameters calculated by statistical moment's theory as MDT is while Level $\mathrm{C}$ requires the calculation of an in vitro parameter that expresses a global drug dissolution performance as is the case of DE. 
Table 4: Criteria used for selection of the best-fit model, mean, $n=12$

\begin{tabular}{|c|c|c|c|c|c|c|c|c|}
\hline USP Apparatus & Dose & First-order & Higuchi & Korsmeyer-Peppas & Hixson-Crowell & Makoid-Banakar & Weibull & Logistic \\
\hline \multicolumn{9}{|l|}{$\mathrm{R}^{2}$ adjusted } \\
\hline \multirow[t]{2}{*}{2} & Low & 0.7321 & 0.5455 & 0.9814 & 0.4621 & 0.9954 & 0.9971 & 0.9733 \\
\hline & High & 0.6002 & 0.3488 & 0.9707 & 0.2511 & 0.9956 & 0.9985 & 0.9813 \\
\hline \multirow[t]{2}{*}{4} & Low & 0.9396 & 0.9228 & 0.9815 & 0.9222 & 0.9968 & 0.9975 & 0.9905 \\
\hline & High & 0.9341 & 0.9173 & 0.9731 & 0.9208 & 0.9972 & 0.9978 & 0.9814 \\
\hline \multicolumn{9}{|l|}{ AIC } \\
\hline \multirow[t]{2}{*}{2} & Low & 78.67 & 86.10 & 48.43 & 87.48 & 30.40 & 20.86 & 50.97 \\
\hline & High & 80.02 & 87.77 & 51.77 & 88.66 & 28.18 & 11.80 & 38.84 \\
\hline \multirow[t]{2}{*}{4} & Low & 44.11 & 52.46 & 34.18 & 48.16 & 13.34 & 10.77 & 24.50 \\
\hline & High & 44.61 & 48.39 & 33.40 & 47.04 & 8.59 & 4.69 & 27.65 \\
\hline
\end{tabular}

As Weibull function was the best-fit model $T d$ values were calculated and dissolution profiles were compared with these values. No significant differences were found between low and high dose $(* \mathrm{P}>0.05)$. Results are shown in table 5 .

Table 5: Weibull parameters and $T d$ values derived from data adjusted to this mathematical model, mean, $n=12$

\begin{tabular}{lllll}
\hline USP Apparatus & Dose & $\boldsymbol{\alpha}$ & $\boldsymbol{\beta}$ & $\boldsymbol{F}_{\max }$ \\
\hline 2 & Low & 4.56 & 0.53 & 109.55 \\
& High & 4.40 & 0.57 & 103.50 \\
4 & Low & 58.02 & 1.11 & 40.25 \\
& High & 77.27 & 1.22 & 30.34 \\
\hline
\end{tabular}

$* \mathrm{P}<0.05$, Low vs. High dose.

\section{Model-dependent comparisons}

Considering established criteria to choose the best-fit model (highest $\mathrm{R}^{2}$ adjusted and lowest AIC values) Weibull function was the best mathematical model to explain in vitro dissolution performance of carbamazepine from reference tablets. Results are shown in table 4

In this in vitro equivalence study of low and high dose, data fitting to mathematical equations previously described were carried out without any physiological significance in order to find a mathematical model that explains the in vitro dissolution behavior of carbamazepine from Mexican reference products. The purpose of using mathematical models to adjust in vitro dissolution data is that they facilitate the analysis and interpretation of observed results and because they describe the dissolution profiles as a function of only a few parameters that can be easily statistically compared [26].

Dissolution study of two doses of carbamazepine reference tablets carried out with USP paddle apparatus and flow-through cell method reveals similar dissolution profiles in each USP apparatus. The manufacturing process of reference tablets and dissolution conditions used allowed the complete release of the drug under official conditions. It is important to highlight that these reference tablets show congruence between doses in two different systems what represents a product of good quality and ensures the proper biowaiver of low dose. This is not always the case. Medina et al., [27] studied two doses of metronidazole reference tablets (250-mg and 500-mg) using USP basket apparatus and flow-through cell method with pharmacopeial dissolution medium 0.1 $\mathrm{N}$ hydrochloric acid) and dissolution process was different in each dose and in each USP apparatus.

Despite low solubility of carbamazepine, it is significant the compliance of pharmacopeial criteria of 400-mg tablets (dissolution criteria at 15 and $60 \mathrm{~min}$ are only for $200-\mathrm{mg}$ tablets) however, the main problem identified in this comparative study was the low dissolution rate and extent of carbamazepine with USP Apparatus 4 . The flow-through cell apparatus is an equipment that better reflects in vivo environment of the gastrointestinal tract and it is an appropriate option to find a significant IVIVC for drugs with solubility problems. On this apparatus, several authors have reported a better estimate of absorption rate (which is a better predictor of in vivo dissolution) of cilostazol and diclofenac sodium $[15,16]$ both poorly soluble drugs.

In order to develop suitable in vitro dissolution tests, it is important to document dissolution performance of all carbamazepine doses of reference tablets in dissolution media with $\mathrm{pH}$ of physiological relevance $(\mathrm{pH} \mathrm{1.2,4.5,} \mathrm{and} \mathrm{6.8)} \mathrm{as} \mathrm{well} \mathrm{as} \mathrm{studies} \mathrm{with} \mathrm{flow-through}$ cell method. Satisfactory dissolution conditions should predict in vivo absorption to avoid clinical problems. Several authors have found significant differences in plasma patients undergoing therapy with this drug [28] and loss of seizure control when a drug product is exchanged for another formulation [29]. In the present in vitro equivalence study, similar dissolution performance of two doses of carbamazepine reference tablets, independently of USP apparatus used, was found. The study was carried out with $1 \%$ sodium lauryl sulfate aqueous solution as dissolution medium. If this performance is observed with dissolution media of physiological relevance it is possible to suggest waiver of in vivo studies for lower carbamazepine dose since bioavailability will be proportional to the highest dose. More research on this field is necessary for all available doses of reference drug products since the quality of generic formulations depends on the quality of references.

\section{CONCLUSION}

Similar dissolution performance of two doses of carbamazepine reference tablets was found in each USP dissolution apparatus used. Dissolution performance of carbamazepine shows a dependence on the hydrodynamic conditions to which tablets were subjected. The main problem identified in this comparative study is the low dissolution rate and extent found with USP Apparatus 4. More research on this field is necessary for all available doses of reference drug products since the quality of generic formulations depends on the quality of references.

\section{AUTHORS CONTRIBUTIONS}

All the author have contributed equally

\section{CONFLICT OF INTERESTS}

\section{Declared none}

\section{REFERENCES}

1. Food and Drug Administration. Guidance for Industry: Waiver on in vivo bioavailability and bioequivalence studies for immediate-release solid oral dosage forms based on a biopharmaceutics classification system; 2017. Available from: https://www.fda.gov/downloads/Drugs/Guidances/ucm0702 46.pdf. [Last accessed on 20 Mar 2019].

2. Lennernas $\mathrm{H}$, Abrahamsson B. The use of biopharmaceutical classification of drugs in drug discovery and development: current status and future extension. J Pharm Pharmacol 2005;57:273-85. 
3. International Pharmaceutical Federation. Biowaiver monographs. Available from: https://www.fip.org/ bcs_monographs. [Last accessed on 20 Mar 2019]

4. Barhate S, Husain M. Development of hydrophilic matrix tablet of carbamazepine using $3^{3}$ full factorial experimental designs. Int J Pharm Pharm Sci 2015;7:369-75.

5. Food and Drug Administration. Guidance for Industry: Dissolution testing of immediate release solid dosage forms; 1997. Available from: https://www.fda.gov/downloads/ drugs/guidances/ucm070237.pdf. [Last accessed on 20 Mar 2019].

6. United States Pharmacopeia and National Formulary USP 41NF 36; The United States Pharmacopeial Convention, Inc: Rockville MD: 2018.

7. Castro N, Jung H. Determination of absorption profiles of carbamazepine products by the deconvolution method and its correlation with in vitro data. Rev Mex Cienc Farm 2000;31:42-6.

8. Jung $\mathrm{H}$, Milan RC, Girard ME, Leon F, Montoya MA. Bioequivalence study of carbamazepine tablets: in vitro/in vivo correlation. Int J Pharm 1997;152:37-44.

9. Singh I, Aboul Enein HY. Advantages of USP apparatus IV (flowthrough cell apparatus) in dissolution studies. J Iran Chem Soc 2006;3:220-2.

10. Qui S, Wang K, Li M. In vitro dissolution studies of immediaterelease and extended-release formulations using flow-through cell apparatus 4. Dissol Technol 2014;21:6-15.

11. Sunesen VH, Pedersen BL, Kristensen HG, Müllertz A. In vivo in vitro correlations for a poorly soluble drug, danazol, using the flow-through dissolution method with biorelevant dissolution media. Eur J Pharm Sci 2005;24:305-13.

12. Szymanska E, Winnicka K. Comparison of flow-through cell and paddle methods for testing vaginal tablets containing a poorly water-soluble drug. Trop J Pharm Res 2013;12:39-44.

13. Emara LH, Emam MF, Taha NF, El-Ashmawy AA, Mursi NM. In vitro dissolution study of meloxicam immediate release products using flow-through the cell (USP apparatus 4) under different operational conditions. Int J Pharm Pharm Sci 2014;6:254-60.

14. Fotaki N, Reppas C. The flow-through cell methodology in the evaluation of intralumenal drug release characteristics. Dissol Technol 2005;12:17-21.

15. Jinno J, Kamada N, Miyake M, Yamada K, Mukai T, Odomi M, et al. In vitro-in vivo correlation for the wet-milled tablet of poorly water-soluble cilostazol. J Controlled Release 2008;130:29-37.

16. Jantratid E, De Maio V, Ronda E, Mattavelli V, Vertzoni M, Dressman JB. Application of bio-relevant dissolution tests to the prediction of in vivo performance of diclofenac sodium from an oral modified-release pellet dosage form. Eur J Pharm Sci 2009;37:434-41.

17. COFEPRIS. Listado actualizado de medicamentos de referencia 2017/08, Mexico. Available from: https://www.gob.mx/ cms/uploads/attachment/file/197452/lMR_2017-

08_V006.pdf. [Last accessed on 20 Mar 2019]

18. Yuksel N, Kanik AE, Baykara T. Comparison of in vitro dissolution profiles by ANOVA-based, model-dependent and independent methods. Int J Pharm 2000;209:57-67.

19. Zhang Y, Huo M, Zhou J, Zou A, Li W, Yao C, et al. DDSolver: an add-in program for modeling and comparison of drug dissolution profiles. AAPS J 2010;12:263-71.

20. Medina JR, Hernandez J, Hurtado M. In vitro release studies of carbamazepine tablets and benzoyl metronidazole suspensions using the flow-through cell apparatus and simulated gastrointestinal fluids. Int J Appl Pharm 2017;9:54-60.

21. Langenbucher F, Benz D, Kurth W, Moller H, Otz M. Standardized flow-cell method as an alternative to existing pharmacopoeial dissolution testing. Pharm Ind 1989;51:127681.

22. Budikayanti A, Chaliana C, Luoisa M, Setiabudy R. Development and validation of carbamazepine plasma concentrations measurement and its application on epilepsy patients. Int J Pharm Pharm Sci 2017;9:87-91.

23. Podczeck F. Comparison of in vitro dissolution profiles by calculating mean dissolution time (MDT) or mean residence time (MRT). Int J Pharm 1993;97:93-100.

24. Anderson NH, Bauer M, Boussac N, Khan Malek R, Munden P, Sardaro M. An evaluation of fit factors and dissolution efficiency for the comparison of in vitro dissolution profiles. J Pharm Biomed Anal 1998;17:811-22.

25. Cardot JM, Beyssac E, Alrici M. In vitro-in vivo correlation: importance of dissolution in IVIVC. Dissol Technol 2007;14:15-9.

26. Adams E, Coomans D, Smeyers Verbeke J, Massart DL. Nonlinear mixed effects models for the evaluation of dissolution profiles. Int J Pharm 2002;240:37-53.

27. Medina JR, Ortiz HD, Hurtado M, Domínguez Ramirez AM. Influence of dose and the USP basket and flow-through cell dissolution apparatus in the release kinetics of metronidazole immediate-release products. Int $\mathrm{J}$ Res Pharm Sci 2014;5:137-46

28. Rentmeester TW, Doelman JC, Hulsman JA. Carbamazepine: branded formulation versus generic formulation. Pharma Weekblad 1990;125:1108-10.

29. Olling M, Mensinga TT, Barends DM, Groen C, Lake OA, Meulenbelt J. Bioavailability of carbamazepine from four different products and the occurrence of side effects. Biopharm Drug Dis 1999;20:19-28. 